\title{
CARBON AND NITROGEN ISOTOPE STUDIES IN AN ARCTIC ECOSYSTEM
}

DOE/ER/60265--6

DE 93010985

\author{
Donald M. Schell \\ Water Research Center \\ Institute of Northern Engineering \\ University of Alaska Fairbanks, Fairbanks, Alaska
}

\section{INTRODUCTION}

This proposal requests funding for the completion of our current ecological studies at the $\mathrm{M}$ s-117 research site at Toolik lake, Alaska. We have been using a mix of stable and radioisotope techniques to assess the fluxes of carbon and nitrogen within the ecosystem and the implications for long-term carbon storage or loss from the tundra. several tentative conclusions have emerged from our study including:

- Tundra in the foothills is no longer accumulating carbon. Surficial radiocarbon abundances show little or no accumulation since $1000-2500$ yrs BP.

- Coastal plain tundra is still accumulating carbon, but the rate of accumulation has dropped in the last few thousand years.

- Carbon export from watersheds in the Kuparuk and Imnavait creek drainages are in excess of that expected from estimated primary productivity. Whether this is linked to the previous two points is unknown at this time. Accelerator radiocarbon dating of dissolved organic carbon to answer this question is in progress.

- Nitrogen isotope abundances vary between species of plants and along hydrologic gradients. We find distinct seasonal cycles in the nitrogen isotope abundances in caribou hooves which may be related to physiological and environmental factors. Such information may allow new insight into physiological condition 


\section{DISCLAIMER}

This report was prepared as an account of work sponsored by an agency of the United States Government. Neither the United States Government nor any agency thereof, nor any of their employees, makes any warranty, express or implied, or assumes any legal liability or responsibility for the accuracy, sompleteness, or usefulness of any information, apparatus, product, or process disclosed, or represents that its use would not infringe privately owned rights. Reference herein to any specific commercial product, process, or service by trade name, trademark, manufacturer, or otherwise does not necessarily constitute or imply its endorsement, recommendation, or favoring by the United States Government or any agency thereof. The views and opinions of authors expressed herein do not necessarily state or reflect those of the United States Government or any agency thereof. 
for caribou and be useful in assessing critical habitat types during the winter season when field studies are difficult.

Relation to ecosystem modeling efforts

The modeling efforts of the R4D Program on stream and watershed ecology reflect the experimental accomplishments and accumulation of baseline information obtained during the past years. Although our rough estimates indicate that nitrogen inputs to the watershed balance losses, the carbon fluxes are not in equilibrium and there is a net loss of carbon from the tundra ecosytem through respiration and transport out of the watershed via Imnavait creek. Radiocarbon profiles of soil sections coupled with mass transport calculations revealed that peat accumulation has essentially ceased in the $R 4 D$ watershed and appears to be in ablative loss. Thus the carbon flux measurements provide validation tests for the predictive models employing data from other primary productivity related studies. These findings are also important in the context of global $\mathrm{CO}_{2}$ increases from positive feedback mechanisms in peatlands associated with climatic warming in the subarctic regions.

In response to the start-up of the NSF-sponsored ITER program at the Toolik lake area, we have attempted to link the goals of that program with the goals of our continuing R4D work. This has led to fruitful synergism with the LTER aquatics group and we are now comparing carbon accumulation/ablation in the vicinity of Toolik lake at the ITER experimental site. In the Kuparuk River project, isotope sudies on the higher trophic levels is being closely coordinated. Toward this end, the IrER has provided the PI with one man-month of salary.

\section{BACKGROUND}

This project has been using natural isotope abundances to trace major pathways of energy flow to consumers in Imnavait creek and the tundra ecosystem of the R4D watershed with comparative work in the coastal tundra. We have now accumulated 
and have processed samples collected at the R4D intensive site over the past three years and are comparing these data with similar samples collected from the coastal plain and from a hydrologic gradient near Toolik Lake. Our overall goals are to

a) determine if there is a net carbon accumulation or loss from upland and coastal tundra;

b) datermine the role of eroded peat carbon in the food webs of the aquatic ecosystem through the use of natural abundances of stable and radioisotopes of carbon;

c) determine the distribution of carbon and nitrogen isotopes in the tundra-pond ecosystem to establish the feasibility of using observed differences as natural tracers of energy and nutrients from plant sources to consumer organisms; and

d) integrate our findings with the modeling efforts and provide validation data on model predictions. These findings will also be coupled with a watershed-linked model focused on the role of dissolved organic carbon dynamics.

Our past work on fishes, birds, and the prey species of insects and aquatic crustaceans has shown that peat carbon is very important in the energy supply supporting the food webs over the course of the year. Obligate freshwater fishes from the coastal lakes and colville River have been shown to contain up to 60 percent peat carbon at the end of the winter season. In contrast, migratory shorebirds and passerines contained much higher radiocarbon abundances indicating a major shift to "recent" in situ primary production in pond and stream ecosystems in summer months. For the past two years, we have narrowed our focus to the processes supplying carbon to the beaded stream system at MS-117 and have concentrated on determining the transfer and accumulation rates of carbon in the watershed. 
In cooperation with Mark Oswood, we have been studying the movement of carbon from the tundra into the pond system through runoff transport of dissolved organic carbon and erosion of peat. We are also considering the movement of organic nitrogen and have analyzed a detailed suite of samples from the summer-87 hydrologic season. This work was continued into the 1988 field season.

The aquatic portion of the R4D program is the logical interface between this small-stream/watershed study and the larger river studies of the NSF-funded LTER program. The PI of this project has been cooperating with the ITER-Kuparuk River study group on measuring the relative transfer rates of peat carbon into larval and adult grayling.

This proposal seeks funding to complete the isotope studies and to investigate processes in consumer organisms that control the distribution of isotope abundances. The goal is to define the major pathways and ecosystem processes that are dependent on modern primary production versus those with substantial dependency on peat carbon as an energy supply. Extrapolation of results to the coastal plain and particularly to the Arctic National Wildife Refuge, may be useful in the design of mitigative measures for industrial development associated with energy resources.

\section{JUSTIFICATION}

An effective model of tundra processes will require well-known boundary conditions and validation data if they are to be useful. The movement of carbon downslope and across the riparian zone needs to be quantifiec in context with the amounts recently fixed by terrestrial plants and by the mobilization of peat organic carbon. Similarly, the relative rates of nitrogen fixation to recycling within the organic layer need to be approximated. We seek to accomplish this by following shifts in the stable isotope ratios in plants along hydrologic gradients 
at MS-117 and at Toolik Lake. The data required for the model will provide insight into the threshold rainfalls and areas where water movement will transport significant quantities of carbon. In contrast to more temperate stream systems where inputs of allochthonous particulate carbon are important energy sources to stream invertebrates, the largest energy source available to aquatic fauna of Imnavait creek is the dissolved organic matter transported from the slopes to the streams by runoff. This, in turn, contrasts with the larger arctic rivers such as the colville where eroded particulate organic matter in the form of peat predominates. To date, however, we do not know the temporal origin of the dissolved organic matter; i.e. is it derived from organic carbon fixed in the past season, over the past few years, or is it derived from vegetative debris produced over many years. This information is critical toward interpretation of our findings that soil profiles indicate cessation of carbon accumulation approximately 1000 - 2700 years B.P.

The most critical aspect of the carbon storage versus decomposition arises in the consideration of the results of either climatic disturbance or localized impacts on the tundra's primary producers. The vast carbon deposits stored in tundra and taiga peats represent a huge potential source of carbon dioxide and methane additions to the atmosphere. Recent projections of impacts made at the DOE Peatlands Workshop in May 1988 showed that a $10 \mathrm{~cm}$ drop in the average peatland water table could release up to $1-3 \mathrm{Pg} / \mathrm{yr}$ of carbon dioxide from peat oxidation. This quantity would be second only to fossil fuel releases. Our findings that surficial peats at MS-117 and in the Kuparuk River valley are over 1000 yrs old may indicate that ablative processes have already begun. We have completed sampling of coastal peats through support from the DOE-CDIAR program and will be analyzing these samples for radiocarbon over the next months. 
This proposal requests funds to complete a series of process studies governing the mobilization of specific types of organic carbon from the arctic tundra ecosystem. Reviewer comments resulting from the presentation and review of past work clearly identify that knowledge concerning the reaction of the organic mat of the watershed and toeslope riparian zone to disturbance is critical toward understanding the movement of carbon out of the ecosystem. This project has consistently recognized the importance of terrestrially derived carbon to the aquatic ecosystem energetics and we have focused on the determining the lability of the peat carbon to perturbations. Integration of the acquired data with the models will serve to describe the spatial movement of carbon in the slopes, riparian zones and aquatic environments of the foothills. Thus our primary emphasis during the next phase of the study will center on the peat carbon - hydrologic transport processes using runoff models developed for MS-117 by D. Kane. In addition, we will continue our studies on natural variations in stable isotope abundances with respect to vegetation, hydrologic gradients, and in the consumer organisms, primarily caribou (see below).

HYPOTHESIS 1. Carbon leaving the watershed is derived primarily from the underlying mat of peat and represents primary production that occurred several tens or hundreds of years previously.

HYPOTHESIS 2. Carbon fixation in upland tussock tundra is in equilibrium with, or is less than, respiration and transport out of the system. only wet mesic tundra in the coastal plain continues to accumulate carbon as peat.

HYPOTHESIS 3. Nitrogen inputs to tundra by precipitation and $N$ fixation are recycled and transported downslope to the riparian zone. Here, partial mineralization to ammonia and nitrate provides the primary nutrient sources for the epilithic algae in the rivers. The recycling enroute is accompanied by loss of the lighter $\mathrm{N}$ isotope thus providing a means of estimating 
fixation/recycling ratios over downslope transects.

our secondary goals will continue to focus on the use of stable and radioisotope abundances as natural tracers of carbon and nitrogen movement from primary producers to the consumers. These food web studies have offered considerable insight into the energetics of aquatic fauna in the past, and our emphasis will be to test the feasibility of using stable isotopes as condition indicators in caribou. This herbivore is one of the principal consumers and the most "valued ecosystem component" in the tundra habitat. Preliminary data on the keratin of caribou hooves have shown that stable isotope ratios vary in response to either food stress or physiological changes during reproductive activities and periods of energy storage. We seek to develop the correlations required to account for these observations and test the following hypothesis.

HYPOTHESIS 4. The oscillations in carbon and nitrogen isotope ratios that are evident in the keratin along the length of caribou hooves represent either physiological stress and/or diet change during winter, or reallocation of body protein during reproductive processes.

Specific objectives include:

1. Compare the amounts and sources of dissolved and particulate organic matter entering Imnavait creek and the Kuparuk River ecosytems through the combined use of quantitative measurements and the natural radiocarbon content in various chemical components;

2. Determine the seasonality and physiological controls on the stable isotope ratios in caribou and investigate the possible usage of these variables as condition indices in wild populations.

3. Correlations with carbon and nitrogen stable isotope 
ratios in vegetation used by caribou over altitudinal gradients (habitat types) will be investigated with respect to seasonal habitat dependencies.

4. Continue studies on the rates of carbon accumulation or ablation in arctic tundra through collection of soil cores and analysis of bulk carbon and radiocarbon content (supplemental funiding from CDIARP). These data will be synthesized in the context of landscape and regional impacts on carbon dioxide fluxes and organic carbon storage in tundra.

5. Through the use of stable and radioisotope abundance techniques, compare and contrast seasonal fluxes of organic carbon to consumers inhabiting the tundra ecosystem. Herbivores and their predators in both tundra and aquatic environments will be sampled in conjunction with ongoing fishery studies by the LTER group from Woods Hole. Caribou and bird studies will be conducted in cooperation with personnel with the USFWS.

6. Prepare and analyze data for publication.

V. GENERAL STRATEGY AND APPROACH

Carbon fluxes in runoff from tundra in the Imnavait creek watershed--Downslope movement of water is constrained to the surficial organic mat and soils by the underlying permafrost. As the seasonal thaw of the active layer progresses, water movement is slowed by the increasing density of the organic mat and is exposed to the highly degraded and weathered peaty materials. Data from the past two years indicate that dissolution of organic matter increases during the summer. By August, the runoff volume and solute concentrations reach annual maxima. The sources of the organic matter are much more problematic. Experiments using litter bags to measure decomposition in the tundra (Flanagan and Bunnell, 1980) found annual weight losses ranging from 14.6 to 32 
percent of the initial dry weight. Eriophorum angustifolium lost a. total of 27 percent per cent of its dry weight annually to decompositional processes at Barrow. Overall, standing dead plant tissue decayed at about 10 pecent per year, whereas soil organic matter decayed much more slowly, $2-2.5$ percent per year. If the exponential decay is calculated for the past 30 years using the rate constant of $0.1 \mathrm{yr}^{-1}$, it implies that only 5 percent of the original plant matter would remain, iut the amount increases to 22 percent if $\mathrm{k}=0.05$.

Figure 1 illustrates the rationale for attempting to determine the source of the DOC through the use of radiocarbon activity. It has been over 25 years since the inputs of radiocarbon to the atmosphere peaked from nuclear weapons testing. The vegetation grown since 1958 has contained elevated radiocarbon concentrations in excess of background so the standing dead and detritus derived from primary production in the past two decades should produce DOC with a similarly elevated 14C content. However, this is not the case noted with either the particulate matter suspended in the streams, surficial sediments from lakes or in organisms which are supported by detrital food webs. In all of these cases, the ${ }^{14} \mathrm{C}$ content is depressed below background indicating that the bulk of the organic carbon is derived from pre-bomb production. This is surprising since the decomposition of the organic matter would be expected to follow an exponential decay with the "high quality" organic matter going first. Furthermore, since some weapons-produced radiocarbon must be present in live roots in surficial peats, the implication is that the average organic carbon atom is derived from several hundreds to thousands of years before present in order that its radiocarbon depression overwhelms the modern contribution. All pre-bomb organic matter can lose radiocarbon only by decay from a uniform starting activity. The implications of an "old" DOC are several.

1. Modern primary production, although essential to herbivores feeding on green vegetation (caribou, voles, lemmings), is not the major source of energy for food webs supporting many of the birds and fishes of the North slope. This 


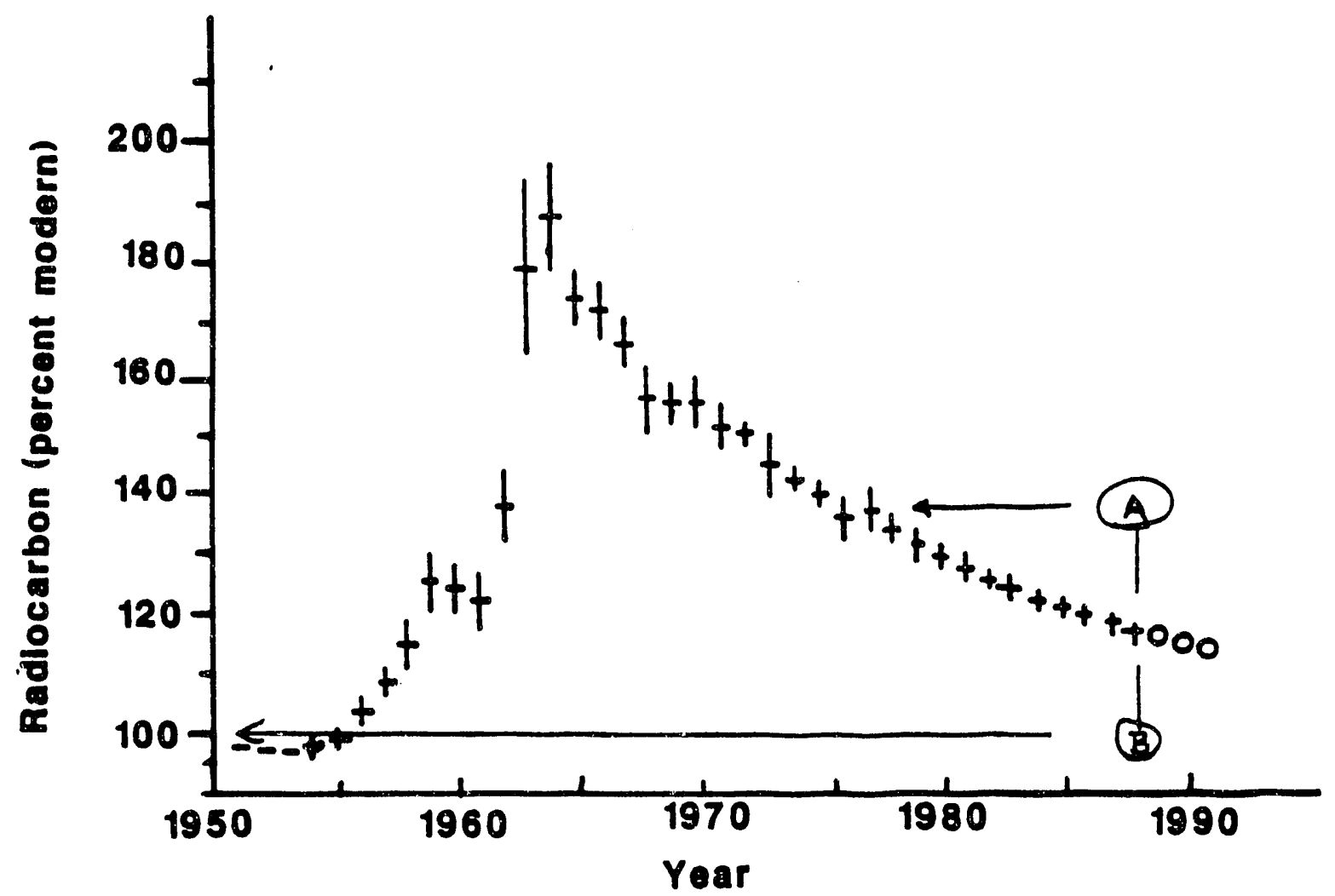

Figure 1. Radiocarbon regimes in arctic vegetation and organic matter. The curve represents radiocarbon activity in North American agricultural products (crosses) for the year indicated. The high bomb radiocarbon content from the 1960 's has been equibrating with surface ocean water and by 1987 was about 119 percent modern. The circles show projected values. A hypothetical sample of dissolved organic matter in runoff at area "A" would indicate that most of the organic carbon was derived from recent production. Values near "B", however, would indicate that the organic matter was derived from production that occurred centuries before 1950 since the elevated ${ }^{14} \mathrm{C}$ of recent material would require a majority of chronologically old organic carbon to dilute the activity to the concentration shown. When considered in context with data on average radiocarbon in the active layer of the soli, this information can provide semiquantitative estimates of temporal sources of carbon. Separation of the dissolved fraction into general classes of compounds (carbohydrates, humic acids, fulvic acids) will also provide relative information on the lability of these materials. (Radlocarbon background data from Kreuger Enterprises, Geochron Laboratories, unpublished). 
has obvious consequences when discussing the "response" to disturbance of tundra primary production.

2. Carbon stocks in the soil organic pool are not in steady state or accumulating. The depression in overall radiocarbon content instead indicates that the soil carbon is being oxidized in excess of production. Furthermore, since the existing stocks of soil organic matter indicate that accumulation occurred in the past, the implication of rapid loss today is that a major change in environmental or biological conditions has taken place. What is this change?

3. Ablative loss of tundra carbon standing stocks in excess of production implies a long-term decrease in the energy available to food webs supported by it. Thus the aquatic ecosystems in which higher trophic levels are supported by insects may be "running down" and major ecological shifts may occur in the future. Schell (1983) and schell and ziemann (1989) have shown that many top consumers have large seasonal dependencies on peat carbon. A decrease in this energy source may constrain overwintering success of fishes that are tightly coupled to the peat-chironomid-fish food chain.

The overall strategy for sampling of soil and stream DOC consists of measuring the temporal and spatial variations in DOC and the dominant chemical constituents. We had planned to collect samples in 1989 through the use of lysimeters in the water track soils and water from Imnavait creek and the Kuparuk River. No field work was funded in 1989, however, and this work was not undertaken. In 1990, water samples will be obtained during the hydrologic season. Subsamples of DOC will be isolated and analyzed for concentration and radiocarbon activity. The small quantities of carbon in the subsamples require the use of accelerator dating techniques with the concommitant expenses and delays. Nevertheless, the ability to determine the probable source of the various fractions will allow insight into the relative rates of biological utilization of the 
various classes of chemical compounds. The recent commercial availability of accelerating dating services offers the possibility of somewhat reduced costs and more rapid turnaround of data.

Stable isotope ratios of carbon and nitrogen in tundra ecosystem components--The hydrological and biological investigations in the Kuparuk River sytem near Toolik have shown that stable isotope ratios are excellent tracers of nutrients and carbon in the aquatic food webs. The PI has been cooperating with the ITER aquatic studies and has provided the radiocarbon data for grayling corroborating the observed shifts from heterotrophic to autotrophic food webs following fertilizer additions to the stream. These studies have shown, however, that the ritrate additions to the streams from riparian seepage comprise a major source of nitrogen. The nitrate is then depleted downstream by epilithic algae (Peterson et al, in prep.). It is not known, however, whether the nitrate arises from downslope transport of inorganic $N$ or from nitrification of mineralized DON in the riparian zone.

We propose to test the premise that downslope recycling of nitrogen in the watertracks coupled with uptake by plants controls the arailable nitrate-N in soil solution. A series of small plots will be devegetated by hand picking and lysimetered soil solutions will be measured for increases in nitrate content relative to the concentrations of DON. The stable $N$ isotope ratios in the DON will then be compared to see if enrichment in ${ }^{14} \mathrm{~N}$ occurs along the downslope transect. The values obtained will finally be compared to DON in the receiving waters of Imnavait Creek and the Kuparuk River. This will test Hypothesis 4 which states that final stream del ${ }^{15} \mathrm{~N}$ reflects the sum of downslope $\mathrm{N}$ recycling and $\mathrm{N}$ fixation.

To quantify the transport of DOC and DON, we will use the suppreting data from the R4D hydrological group. This comprehensive data set will allow correlation of hydrologic events and seasonal inputs with other climatological variables. When coupled with flow data, these data will allow estimation of carbon and nitrogen transport rates out of the system by stream flow. 
Stable isotope ratio oscillations in caribou--This phase of the program involves continuing cooperation with personnel involved with studies on the porcupine caribou herd which migrates through the eastern part of the Brooks Range. Caribou hooves collected from ANWR and from near Toolik Lake have been sampled along their lengths for stable isotope abundances and the oscillations will be related to seasonal changes and migrational patterns as indicated by the temporal spans. We ar underway with this work and have analyzed several hooves to date. Stable isotope ratios oscillate over ther seasons and reach a period of sharp depletion in both ${ }^{15} \mathrm{~N}$ and ${ }^{13} \mathrm{C}$ in late summer and fall. To calibrate hoof growth rates and dietary effects on stable isotope ratios, we will make use of captive animals at the UAF Large Animal Facility. We have already commenced with measurements of hoof growth rates and have begun sampling keratin in hooves for carbon and nitrogen isotope ratios. The observed isotope ratio oscillations in captive animals will be compared with those in hooves from animals collected at various seasons in the wild. We have already been supplied with hooves, muscle tissue and fat samples from 16 documented animals collected as part of a U.S. Fish and Wildlife study. This opportunity for extending our findings regarding the stable isotope regimes in the tundra at the R4D site to physiological and energetics studies of this major consumer is fortunate.

Mass Spectrometry -- Vegetation samples have been collected from differing microenvironments at the R4D site from ridgetops to the riparian zone of Imnavait creek. Where possible, similar taxa have been collected at each site, and these were subdivided to roots, stems, leaves, etc when possible. The goal of this work is to identify the sources of the large isotopic variations observed in consumers and to establish the presence or absence of environmental conditions leading to pronounced changes in isotope ratios within small geographical regions. We have already analyzed samples from MS-117 and have collected another full suite from the ITER site at Toolik lake. Comparative samples have been collected from the oliktok Point and Ugnuravak creek area for comparison with 
the R4D site. This background data set will be supplemented as needed to complete the picture of $\mathrm{N}$ cycling along the hyaraulic gradients.

VI. QUALITY ASSURANCE (QA) AND QUALITY CONTROL (QC)

This research unit will subscribe to accepted techniques of quality control in analytical procedures. Although many of the specialized experimental methods are not considered standard methodologies, the procedures employed will ensure maximum precision in sampling and laboratory analysis. Accuracy will be tested regularly through the use of accepted standards and internal standards where applicable.

Carbon and nitrogen isotope ratios--samples for stable isotope ratio analysis (SIRA) will be subjected to the following QC and QA methods. All vegetation samples and animal tissues will be dried and ground to fine powder for subsampling. Since contamination by small amounts of artificially enriched $13 \mathrm{C}$ or $15 \mathrm{~N}$ would seriously affect samples, we will strive to package all samples in the field and not return them unprotected to the Toolik laboratories. Parts of the vegetation and the ground subsample will be retained as a voucher for identification and possible replicate analysis.

SIRA samples will be run against secondary standards of organic matter which are treated identically to samples throughout the entire preparatory procedure. We have maintained several standards in the laboratory at Fairbanks, and these are cross-calibrated with other SIRA laboratories around the country. We maintain a continual interlab comparison with the University of Texas and the Marine Biological Laboratory at Woods Hole.

Actual SIRA determinations are made on splits of the carbon dioxide and nitrogen gas from the samples. Periodically, splits of a given sample are run on succeeding days to test for machine variability. Isotope ratios are calculated by analyzing six subsamples against our reference gas standard and averaging the results.

Chemical analyses for dissolved organic carbon.--The 
analyses for DOC are performed on a Technicon Autoanalyzer using standard methods. Analyses are checked both by replicate sampling in the field and by the periodic addition of internal standards to samples of water being analyzed.

Radiocarbon analyses--Due to the high costs of replicate radiocarbon analyses, only limited replication will be employed. past quality assurance samples sent to the commercial laboratory currently used have yielded consistently good replication and we will continue using their service. Past experience has made plain the need for extreme caution in collecting and handing radiocarbon samples in the vicinity of artificial 14C usage. Primary production studies and tracer studies using radiocarbon necessitates that any natural abundance samples be scrupulously maintained at a distance. We to process all. radiocarbon samples either in our "clean" facilities in Fairbanks or in a tent remote from the Toolik facilities wherein artificial radiocarbon may have been used.

\section{LITERATURE CITED}

Flanagan, P.W. and F. L. Bunnell. 1980. Microflora activities and decomposition. In: An Arctic Ecosystem, J. Brown et al. eds. Pp 291-334. Dowden, Hutchinson and Ross, Stroudsburg, PA.

Schell D. M. 1983. Carbon-13 and carbon-14 abundances in Alaskan aquatic organisms: delayed production from peat in arctic food webs. Science 219:1068-1071.

Schell, D. M. and P. J. Ziemann. 1989. Natural carbon isotope tracers in arctic aquatic food webs. In: stable Isotopes in Ecological Research, P.Rundel, J. Ehleringer, and $K$. NagY (eds.). Progress in Ecology Series 68, Springer-verlag. 

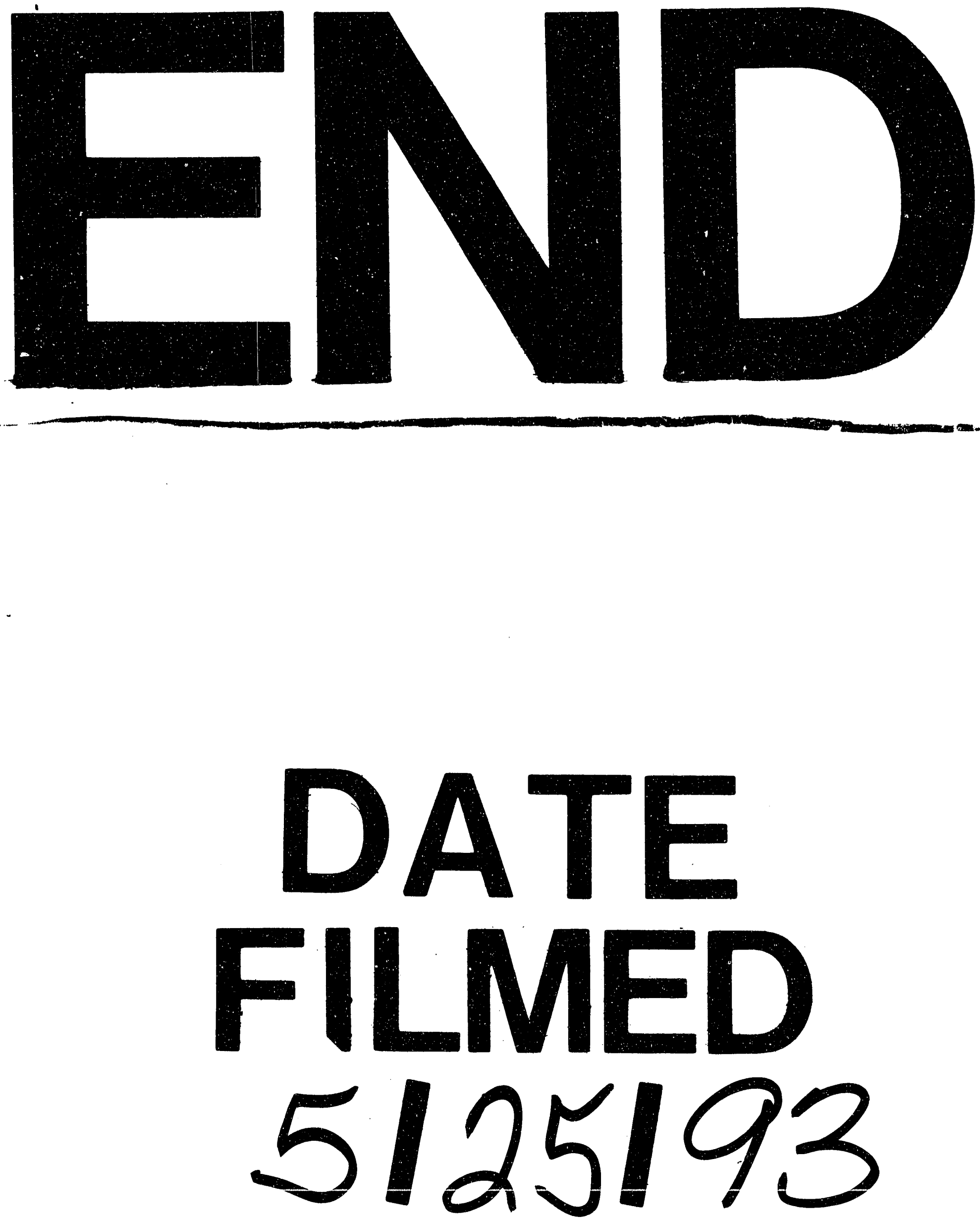
